\title{
Perforated peptic ulcer in Israel
}

\author{
S. LAZARUS \\ From the Southern General Hospital, Glasgow
}

EDITORIAL SYNOPSIS This paper provides an interesting comparison of the incidence of acute perforation of peptic ulcers between Scotland and Israel. The general pattern is very similar in the two countries but the incidence in Israel is only one sixth of that in Scotland.

It is known that the incidence of gastric and duodenal ulcer varies in different parts of the world (Welsh and Wolf, 1960) and that there are major differences throughout the world in the age-adjusted mortality rate from peptic ulcer (Segi, Fujisaku, and Kurichara, 1959). Thus environmental and possibly racial factors may influence the development and course of peptic ulcer.

One of the main problems in the epidemiology of peptic ulcer is the establishment of satisfactory diagnostic criteria and the study of the incidence of acute perforated peptic ulcer partly overcomes this difficulty. Where medical services are adequate a very high proportion of patients with perforated peptic ulcer come under medical attention and the diagnosis is established with certainty, but it is accepted that a study of the incidence of acute perforated peptic ulcer may reflect the liability of an ulcer to perforate rather than the true incidence of peptic ulcer in the population at risk.

The population of the State of Israel is made up largely of Jews, who have come from many different parts of the world and have different social and dietary habits. A survey of acute perforated peptic ulcer in Israel was undertaken in order to study the epidemiology of the condition, particularly in the main communities that constitute its population. Such a survey was made possible because that country has a well-developed hospital service.

Before the survey Dr. H. S. Halevi, of the Israel Ministry of Health, obtained figures from some of the hospitals giving the number of cases of peptic ulcer and the number of cases with perforations admitted. The hospital admissions for peptic ulcer were: duodenal ulcer 2,934 , gastric ulcer 408 , i.e., a ratio of $7: 1$ duodenal to gastric ulcer. The total number of perforated duodenal ulcers was 348 and of perforated gastric ulcers 50 , i.e., also an approximate ratio of $7: 1$. The yearly admission rate for the hospitals listed was 557 for peptic ulcer and 66 for perforated peptic ulcer. These figures can be taken as tentative estimates for they include only six of the hospitals in Israel. They are based on the six-year period 1953-58 with the exception of one hospital, in which the period under survey was 1953-57.

\section{METHOD OF SURVEY}

The case sheets of the patients classified as having had an acute perforated peptic ulcer were examined, and the operation books for the relevant years were surveyed in some hospitals in order to find any cases that had been overlooked. Many case sheets were written in English up to 1955, thereafter a progressively higher proportion was written in Hebrew. In some hospitals a check was made of the patient's card, a personal form on which data concerning the patient's age, sex, and diagnosis are recorded (Israel Central Bureau of Statistics, 1959). A list of the hospitals surveyed and details of the sources of information utilized in the collection of the data are given in Table $\mathbf{I}$.

\section{NUMBER OF SURGICAL BEDS IN ISRAEL}

The Israel Ministry of Health Publication (1960) lists the 25 hospitals in the country which have a total of 1,062 surgical beds. Eight hospitals are known not to accept surgical emergencies and not to admit cases of acute perforated peptic ulcer. The 17 hospitals that admit acute surgical emergencies had a total number of surgical beds of 865 in 1958 and 881 in 1959. Ten of these hospitals were visited and it was thus possible to survey more than $70 \%$ of the acute surgical beds in the country $(72.5 \%$ of the 1958 figures and $73 \cdot 1 \%$ of the 1959 figure).

\section{DATA RECORDED FROM CASE SHEETS}

With the exception of one hospital noted in Table I, 
TABLE I

DETAILS OF 10 HOSPITALS SURVEYED AND OF SOURCES OF INFORMATION

\begin{tabular}{lcccc} 
Hospital & \multicolumn{2}{c}{ No. of Acute Surgical Beds } & Case Sheets Seen & Operation Book Checked Patient's Record Card \\
\cline { 2 - 3 } & 1958 & 1959 & + \\
\hline Hadassah (Jerusalem) & 37 & 37 & + & + \\
Eliezar Kaplan & 45 & 45 & + & + \\
Tel Hashomer & 141 & 60 & + & + \\
Assaf Harrofe & 56 & 64 & + & + \\
Rambam (Haifa) & 64 & 99 & + \\
Tel Aviv (Balfour) & 99 & 47 & + \\
Sharon (Petach Tiquah) & 44 & 76 & + \\
Beilinson (P.T.) & 76 & 41 & + \\
Rothschild (Haifa) & 41 & 34 & + \\
HaCarmel (Haifa) & 34 & 644 & + \\
Total & 637 & & +
\end{tabular}

the case sheet of each case of perforated peptic ulcer was examined. For each case the record no., year, month and day of the perforation, and the country of origin of the individual were collected; the patient's profession, age, sex, and site of the ulcer were also recorded. With regard to the site of ulcer the procedure adopted by Illingworth, Scott, and Jamieson (1944) was followed, namely, if the case sheet contained a definite statement that the ulcer was in the stomach, it was classified as a gastric ulcer; others, situated in the duodenum and those that were in the region of the pylorus were classified as pyloro-duodenal. In this way the difficulty of determining the site of the ulcer in relation to the pyloric sphincter is overcome. Further details recorded were the type of management, e.g., operative treatment, suture, gastro-enterostomy, gastrectomy, and the fate of the individual, whether he recovered or died.

In all hospitals the survey covered the six-year period 1953-1958, in which time details of 354 cases of perforated peptic ulcer in the 10 hospitals were obtained. Cases from earlier and later years were available from some of the hospitals and provided a total of 486 cases. The details from these extra cases were used for some points of the survey. In Table III is listed the number of perforations per year in the hospitals surveyed. It will be noted that despite the steady increase in the total population at risk (1.669 million in 1953 to 2.031 million in 1958$)$ there is no corresponding rise in the number of perforations over the short period of the survey, 1953-1958, during which all the hospitals listed were surveyed. The years 1955 and 1957 have the highest number of perforations. It is of some interest that the short Arab-Israel war occurred at the end of 1956.

\section{INCIDENCE OF ACUTE PERFORATED PEPTIC ULCER}

It is possible to advance a tentative estimate only, as all the hospitals in the country were not surveyed.
If it is accepted, however, that $70 \%$ of the acute surgical beds were surveyed and if the highest yearly figure for perforation is taken, namely 70 cases in 1957 , and a factor applied to it based on the percentage of acute surgical beds surveyed, i.e., 100/70, then it is possible to estimate that 100 cases of perforated peptic ulcer occurred throughout the country in 1957. The total population of Israel in 1957 was estimated at just under 2 million $(1,975,954)$. This gives a rate of 5 per 100,000 per total population per year. This compares with the rate of 33 per 100,000 in south-west Scotland in the year 1953 with a similar estimated population of $2 \cdot 1$ million (Jamieson, 1955). The difference in these figures is so large that it may be taken to be a true reflection of the lower incidence of perforated peptic ulcer in Israel compared with the south west of Scotland. The estimate is not significantly altered if the perforations in Israel are related to the number of Jews only. In 1957 there were 1,762,741, giving an incidence rate of 5.6 per 100,000 . This estimate may be preferable as there is some evidence that Arabs and non-Jews tended to go to the missionary hospitals and therefore may not have been included fully in the hospitals surveyed in this study. In 1958, a $25 \%$ sample survey of hospital admissions revealed an estimated total of 80 cases of perforated peptic ulcer in a population of $1,782,727$ Jews, an incidence of $5 / 100,000$; in 1959 a $12 \frac{1}{2} \%$ sample survey revealed an estimated total of 60 cases on a population of $1,836,151$, an incidence of $4 / 100,000$. These figures, supplied in 1962, support the original estimate based on the percentage of acute surgical beds surveyed.

\section{SEX AND AGE DISTRIBUTION}

The ratio of males to females was 12:1 (Fig. 1). This compares with findings in other series, namely, that of Jamieson (1955) where the 1944-53 figures give a ratio of $12: 1$. An earlier survey, carried out by 


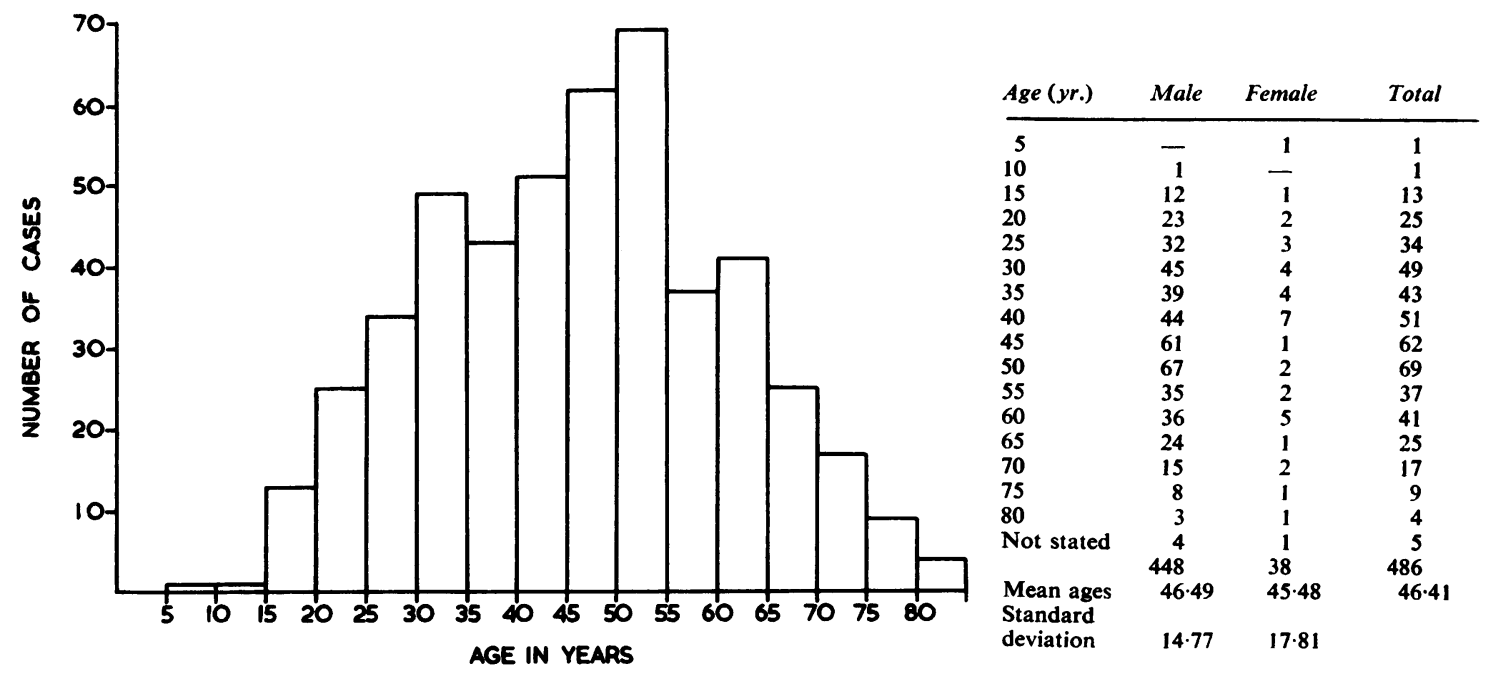

FIG. 1. Distribution of peptic ulcer by age.

Illingworth et al. (1944), gave an even higher ratio of 19 males to one female for the years 1921-43. The general characteristics of the age distribution are shown in Figure 1. The majority of patients fall into the middle age group, namely, 25-60 age groups. Elderly patients are not numerous but are important because of the high mortality rate in the older age groups. Two-thirds of deaths occurred in patients of 60 and over. Mean age at perforation in males is 46.5 years and in females 45.5 years. The incidence at different ages can be obtained by calculating the number of cases of perforation that would occur at the observed rate for each 100,000 people at risk in the differing age groups. Because of the small numbers available in each year the average annual number of cases of perforation in the survey in each age group was used and the distribution of the population by sex and age at December, 1958, used for comparison (Statistical Abstract of Israel 1959/60). The results are given in Figure 2 . It will be seen that there is a progressive rise in incidence up to the 65 and over age group in the males and that high rates are maintained above this age group. Illingworth et al. (1944) found that the incidence reached its maximum between the ages of 35 and 45 in 1941. Later, in 1951, Jamieson (1955) found, in the same area of south-west Scotland, that in each age group the incidence of perforation had risen and peak incidence occurred in the 40,45 , and 50 age groups. Although the incidence of perforation is lower in Israel than in south-west Scotland in each age group, the older age groups, in Israel, carry more of the burden of perforation than the corresponding age groups in south-west Scotland.

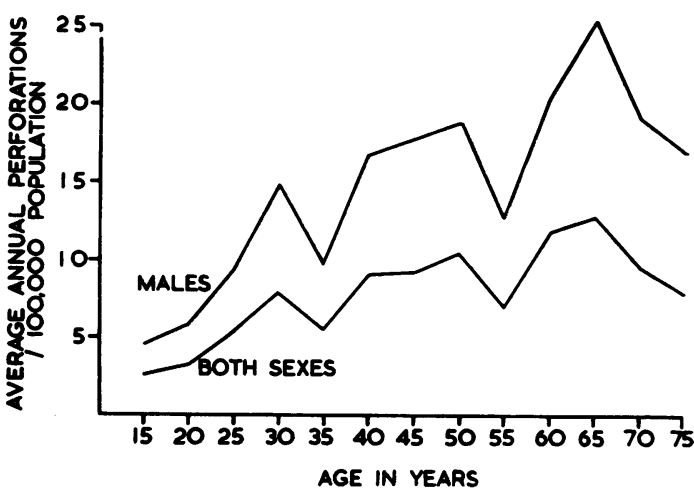

\begin{tabular}{ccc} 
Age Group $(y r)$. & Both Sexes & Male \\
\hline 5 & - & - \\
10 & - & - \\
15 & $2 \cdot 5$ & $4 \cdot 5$ \\
20 & $3 \cdot 1$ & $5 \cdot 8$ \\
25 & $5 \cdot 3$ & $9 \cdot 4$ \\
30 & $7 \cdot 9$ & $14 \cdot 8$ \\
35 & $5 \cdot 4$ & $9 \cdot 8$ \\
40 & $9 \cdot 0$ & $16 \cdot 7$ \\
45 & $9 \cdot 2$ & $17 \cdot 8$ \\
50 & $10 \cdot 4$ & $18 \cdot 9$ \\
55 & $6 \cdot 9$ & $12 \cdot 8$ \\
60 & $11 \cdot 9$ & $20 \cdot 4$ \\
65 & $12 \cdot 9$ & $25 \cdot 3$ \\
70 & $9 \cdot 6$ & $19 \cdot 1$ \\
75 & $7 \cdot 9$ & 17 \\
80 & - & -
\end{tabular}

FIG. 2. Average annual incidence per 100,000 population living in each five-year age group based on figures of the Jewish population by sex and age recorded on 1 December 1958. 
INCIDENCE OF PERFORATION BY MONTHS OF THE YEAR

Figure 3 shows the monthly distribution. Cases occurring in like months in the total survey have been added together. The lowest monthly rates occur in July, August, September, and October. A similar variation in monthly rate was noted by Friedlander (1959) in a survey of perforated peptic ulcer in Israel over a 10-year period in one hospital. However, statistical analysis of the figures in the present survey shows that there are no significant differences between the months.

It would appear that the incidence of perforation of peptic ulcer in Israel is not affected by changes associated with the calendar months, e.g., temperature and humidity.

Illingworth et al. (1944) suggested that the lower rates of incidence of perforated peptic ulcer which they observed in August, September, and October in south-west Scotland may be related to the period of the annual holiday in the area, usually two weeks in July. In Israel there is no official annual holiday except for schoolchildren.

\section{INCIDENCE OF PERFORATION BY DAYS OF THE WEEK}

Perforations occurring on like days of the week have been added together (Fig. 4). There are significant

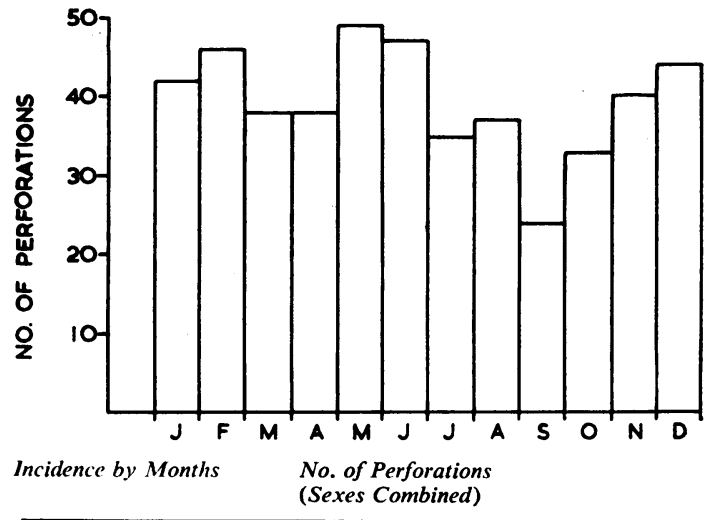

\begin{tabular}{lr}
\hline January & 42 \\
February & 46 \\
March & 38 \\
April & 38 \\
May & 49 \\
June & 47 \\
July & 35 \\
August & 37 \\
September & 24 \\
October & 33 \\
November & 40 \\
December & 44 \\
Not stated & 13 \\
Total & 486
\end{tabular}

FIG. 3. Incidence of perforated peptic ulcer according to the month of the year. variations in incidence between the days of the week $\left(\chi^{2}=12.86 \mathrm{P}<0.05\right)$. Small numbers of cases occur on Saturday and Sunday and a large number of cases on Tuesday. The small number of cases on Saturday and Sunday may be related to the fact that in Israel Saturday is observed, fairly universally, as the day of rest. Most workers cease work early on Friday afternoon and do not return until Sunday morning. Examination of the daily rate of perforations recorded by Jamieson (1955) in the south-west of Scotland also shows significant differences between the days of the week ( $\chi^{2}$ test). A high number occur on Friday and a low number on Sunday. It is of interest to note that the lowest daily rate occurs on and day of rest in each series, i.e., Saturday in Israel the Sunday in south-west Scotland.

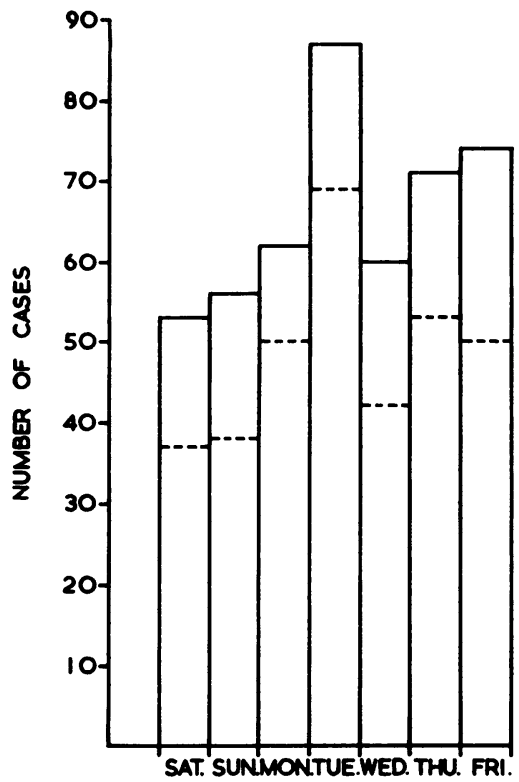

\begin{tabular}{lcc} 
Day of the Week & Whole Series & $1953-58$ \\
\hline Saturday & 53 & 37 \\
Sunday & 56 & 38 \\
Monday & 62 & 50 \\
Tuesday & 87 & 69 \\
Wednesday & 60 & 42 \\
Thursday & 71 & 53 \\
Friday & 74 & 50 \\
Not stated & 23 & 15 \\
Total & 486 & 354 \\
FIG. 4. Incidence of perforated peptic ulcer by days of the \\
week.
\end{tabular}

A comparison of Israel and south-west Scotland according to incidence by days of the week does not show a significant difference $\left(\chi^{2}\right.$ test). The more marked peak on Tuesday in the Israel survey is difficult to explain at present. 


\section{RELATIVE INCIDENCE OF PERFORATION AT DIFFERENT SITES}

Table II gives the site of perforated ulcers according to sex. Pyloro-duodenal perforations account for $91 \%$ of all perforations. Gastric perforations account for $6 \%$. The ratio of pyloro-duodenal to gastric perforations varies according to the sex, 16:1 in the male and 8:1 in the female. As in other series pyloro-duodenal perforations far exceed all other types. The corresponding figures in Jamieson's (1955) survey ware $87 \%$ pyloro-duodenal perforations and $5 \%$ gastric perforations. There are no significant differences between the percentage of females with gastric ulcer perforation and the percentage of females with pyloro-duodenal ulcer perforation (Table III).

TABLE II

SITE OF PERFORATION IN BOTH SEXES

\begin{tabular}{lrcrl} 
Site & Male & Female & Total & Female (\%) \\
\hline Gastric & 25 & 4 & 29 & $13 \cdot 8$ \\
Pyloro-duodenal & 408 & 33 & 441 & $7 \cdot 5$ \\
Stomal & 2 & - & 2 & \\
Not stated & 13 & 1 & 15 & \\
& 448 & 38 & 486 &
\end{tabular}

\section{DEATHS FROM PERFORATED PEPTIC ULCERS}

In the total survey of 486 cases there are 65 deaths. This gives an overall fatality rate of $13.2 \%$. The outcome was not stated in 18 cases. Table III shows the fatality rate by calendar years. It will be noted that there is a considerable variation from year to year and no trend is apparent. Jamieson (1955) has shown, in south-west Scotland, that the fatality rate decreased steadily from 1924 to 1952 . A fatality rate of $13 \%$, corresponding to the Israel figure, was present in the mid-forties (1946). Many factors may influence the outcome of perforated peptic ulcer in an individual patient. Information is available on a few of these factors, namely, the age of the patient, the site of the ulcer, the sex, and the season of the year. Delay in treatment is known to have a profound

\section{TABLE III}

\begin{tabular}{llrr}
\multirow{2}{*}{ Year } & \multicolumn{2}{c}{ FATALITY RATE BY CALENDAR YEARS } \\
& \multicolumn{2}{c}{ No. of Perforations } & Fatality Rate (\%) \\
\cline { 2 - 3 } & Total & Died & \\
\hline 1953 & 53 & 12 & $22 \cdot 6$ \\
1954 & 54 & 6 & $11 \cdot 1$ \\
1955 & 63 & 3 & $4 \cdot 7$ \\
1956 & 60 & 13 & $21 \cdot 6$ \\
1957 & 70 & 6 & $8 \cdot 5$ \\
1958 & 54 & 8 & $14 \cdot 8$ \\
1959 & 47 & 7 & $14 \cdot 8$
\end{tabular}

effect on the outcome. Detailed figures on the interval between the time of perforation and time of operation were not available for all cases in the Israel series but it may be noted that of the 65 patients who died, eight patients were described as moribund on admission and in 10 patients a delay of 24 hours or more was recorded between the presumed time of the perforation and admission to hospital. Delay in seeking treatment and/or the very poor condition on admission was a significant factor in $23 \%$ of the cases that died, i.e., 15 of the 65 deaths. No operation was carried out in 22 of the 65 cases that died. As has been noted in other series, delay in treatment influenced the outcome adversely in a high proportion of the cases that did not survive.

\section{DEATHS BY AGE GROUPS IN MALES AND FEMALES}

Age has a profoundly adverse effect on the outcome of perforation of peptic ulcer. In this series, 44 of the 65 deaths occurred in subjects aged 60 or more (Table IV). The influence of age on fatality rates in males who have perforated is shown in Figure 5. There were no deaths in the 67 cases aged less than 30 years. A progressive rise in fatality rates occurs thereafter and is particularly noted in the group aged 60 and over. The overall fatality rate in females was $18.4 \%$ and $12.9 \%$ in males. However, there are no significant differences between the sexes in the fatality rates in two age groups (30-59 and 60 and over) nor is there a significant difference in the age at death (Table IV).

\section{TABLE IV}

\begin{tabular}{|c|c|c|c|c|}
\hline \multirow{3}{*}{ Age } & \multicolumn{4}{|c|}{ FATALITY RATES (MALE AND FEMALE) } \\
\hline & \multicolumn{2}{|l|}{ Males } & \multicolumn{2}{|l|}{ Females } \\
\hline & Deaths & No. of Cases & Deaths & No. of Cases \\
\hline $30-59$ & 18 & 291 & 2 & 20 \\
\hline $60-$ & 39 & 86 & 5 & 10 \\
\hline N.S. & 1 & 4 & & 1 \\
\hline $\begin{array}{l}\text { Mean age at } \\
\text { death } \\
\text { Standard }\end{array}$ & $59 \cdot 56$ years & & 63.57 years & \\
\hline deviation & 12.61 years & & 12.69 years & \\
\hline
\end{tabular}

DEATHS BY SEASON OF THE YEAR

The fatality rates are higher in the winter months (October to March) than in the summer (April to September) (Fig. 6). The winter rate was $16.9 \%$ (41 deaths in 243 cases) as against the summer rate of $10 \%$ (23 deaths in 230 cases). The difference between the fatality rates for April-September and those of October-March is significant $(P<0.05)$. Figure 6 shows this pronounced seasonal variation graphically. The lower rates occur in May, June, 


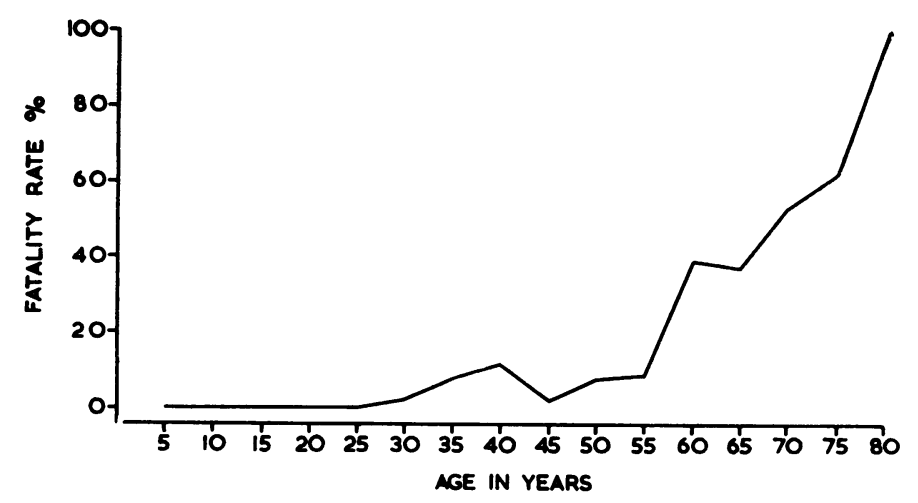

\begin{tabular}{|c|c|c|c|c|c|}
\hline \multirow[b]{2}{*}{ Age } & \multicolumn{3}{|l|}{ Males } & \multicolumn{2}{|c|}{ Females } \\
\hline & Total & Died & $\begin{array}{l}\text { Fatality } \\
\text { Rate }(\%)\end{array}$ & Total & Died \\
\hline 5 & - & - & - & 1 & - \\
\hline 10 & 1 & - & - & - & - \\
\hline 15 & 12 & - & - & 1 & - \\
\hline 20 & 23 & - & - & 2 & - \\
\hline 25 & 31 & - & - & 3 & - \\
\hline 30 & 45 & 1 & 2 & 4 & - \\
\hline 35 & 39 & 3 & $7 \cdot 7$ & 4 & - \\
\hline 40 & 44 & 5 & $11 \cdot 3$ & 7 & 1 \\
\hline 45 & 61 & 1 & 2 & 1 & - \\
\hline 50 & 67 & 5 & 7.5 & 2 & - \\
\hline 55 & 35 & 3 & $8 \cdot 6$ & 2 & 1 \\
\hline 60 & 36 & 14 & 39 & 5 & 1 \\
\hline 65 & 24 & 9 & 37.5 & 1 & 1 \\
\hline 70 & 15 & 8 & 53 & 2 & 1 \\
\hline 75 & 8 & 5 & $62 \cdot 5$ & 1 & 1 \\
\hline 80 & 3 & 3 & 100 & 1 & 1 \\
\hline N.S. & 4 & 1 & & i & - \\
\hline
\end{tabular}

FG. 5. Fatality rates by age for males.

July, and August and thereafter the rate rises, reaching a peak in November. A somewhat similar season variation in percentage mortality rate was noted by Jamieson (1955). As in the present survey, the lowest rates were noted in the summer months of May, June, and July, but the peak percentage mortality rate occurred in January. Jamieson (1955) pointed out that the pattern observed resembled the serial changes in deaths certified as due to respiratory diseases in Scotland and that pulmonary complications may account for the seasonal change in fatality rates from perforations.

\section{DISCUSSION}

The epidemiology of acute perforated peptic ulcer in Israel shows many similarities to that noted in south-west Scotland by Illingworth et al. (1944) and Jamieson (1955).

In particular there is in both countries a marked excess of males afflicted (12:1) and a very high proportion of pyloro-duodenal ulcer perforations compared with gastric. The lowest daily rate of incidence occurs on the day of rest in both series,

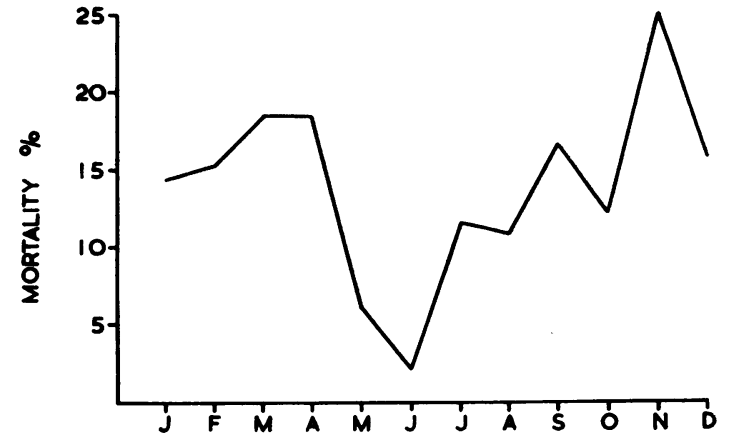

\begin{tabular}{|c|c|c|c|c|}
\hline Month & Total Cas & ses Died & Not Stated & Percentage Monthly \\
\hline January & 42 & 6 & 2 & $14 \cdot 2$ \\
\hline February & 46 & 7 & 2 & $15 \cdot 2$ \\
\hline March & 38 & 7 & - & $18 \cdot 4$ \\
\hline April & 38 & 7 & - & $18 \cdot 4$ \\
\hline May & 49 & 3 & 2 & $6 \cdot 1$ \\
\hline June & 47 & 1 & 1 & $2 \cdot 1$ \\
\hline July & 35 & 4 & - & $11 \cdot 4$ \\
\hline August & 37 & 4 & - & 10.8 \\
\hline September & 24 & 4 & 1 & $16 \cdot 6$ \\
\hline October & 33 & 4 & 1 & $12 \cdot 1$ \\
\hline November & 40 & 10 & 1 & 25 \\
\hline December & 44 & 7 & - & 15.9 \\
\hline \multirow[t]{3}{*}{ Not stated } & 13 & $i$ & 11 & $13 \cdot 37$ \\
\hline & 486 & 65 & 21 & $13 \cdot 37$ \\
\hline & \multicolumn{2}{|r|}{ Cases } & Died & Rate (\%) \\
\hline \multirow{2}{*}{\multicolumn{2}{|c|}{$\begin{array}{l}\text { Oct.-Mar. } \\
\text { Apr.-Sept. }\end{array}$}} & 243 & 41 & $16 \cdot 9$ \\
\hline & & 230 & 23 & 10 \\
\hline
\end{tabular}

FIG. 6. Deaths from perforated peptic ulcer by season of the year.

Saturday in Israel and Sunday in south-west Scotland, and lends support to the hypothesis that rest has a protective effect on peptic ulcer with regard to perforation. The monthly mortality rates are significantly lower in the summer and autumn months both in Israel and in Scotland but there is no significant difference in the monthly incidence rate in Israel. 
The most striking difference occurs in the annual incidence of acute perforated peptic ulcer, $5: 100,000$ in Israel and 33:100,000 population in south-west Scotland. This suggests that the incidence of peptic ulcer itself is considerably lower in Israel than in south-west Scotland.

The age-adjusted death rate for duodenal ulcer per 100,000 males also suggests this, being 3.19 in Israel and 10.34 in Scotland in 1954-55 (Segi et al., 1959). The difference in the distribution of blood groups in the two populations may be of relevance in this respect and may reflect constitutional differences. In south-west Scotland, blood group $\mathbf{O}$ was found in $53 \%$ of 5,898 consecutive new blood donors (Peebles Brown, Melrose, and Wallace, 1956) and in only $35.8 \%$ in 12,000 of the population of Israel (Dressler, 1951). There is an established relationship between blood group $\mathrm{O}$ and duodenal ulcer, as a significant excess of persons of blood group $O$ has been found among sufferers from duodenal ulcer (Clarke, Cowan, Edwards, Howel-Evans, McConnell, Woodrow, and Sheppard, 1955).

The incidence of perforated peptic ulcer in the different communities that constitute the population of the State of Israel is the subject of a further report.

\section{SUMMARY}

A retrospective survey of perforated peptic ulcer in the State of Israel during 1953-58 is compared with a similar survey carried out by Illingworth et al. (1944) in south-west Scotland. The estimated rate of perforation in Israel, 5 per 100,000 population, is only one sixth of the rate in south-west Scotland.

The lowest daily rate of perforations occurs on the day of rest in each country, Saturday in Israel and Sunday in south-west Scotland. There was no significant difference in the monthly incidence of perforation in the Israel series. Other features, e.g., age at perforation, sex ratio, site of perforation, seasonal variation in mortality, etc., were comparable in the two series.

This survey was carried out during the tenure of a W.H.O. Fellowship in 1961, and it was made possible by the generous cooperation of many colleagues and record officers in the Israel hospitals. It is a pleasure to acknowledge help received from Dr. D. Birnbaum, Hadassah Hospital, Jerusalem, Dr. G. Kallner, Israel Bureau of Statistics, who supplied the figures relating to the population of Israel, and Dr. H. S. Halevi, of the Israel Ministry of Health. Dr. E. Friedlander, Tel Aviv, Dr. Z. Yosipovitch, Jerusalem, Dr. King, Tel Hashomer, Dr. J. Naftalin, Haifa, and Mr. Dov Sussman were all generous in their assistance.

My thanks are due to Mr. R. Ainslie Jamieson for his guidance and encouragement, to $\mathrm{Dr}$. R. A. Robb, Mathematics Department, University of Glasgow, for statistical analysis, and to Miss F. French for untiring secretarial help.

\section{REFERENCES}

Brown, D. A. Peebles, Melrose, A. G., and Wallace, J. (1956). The blood groups in peptic ulceration. Brit. med. J., 2, 135-138.

Clarke, C. A., Cowan, W. K., Edwards, J. W., Howel-Evans, A. W. McConnell, R. B., Woodrow, J. C., and Sheppard, P. M (1955). The relationship of the ABO blood groups to duodenal and gastric ulceration. Brit. med. J., 2, 643-646.

Dressler, L. (1951). The blood group distribution among the Jews in Israel. Proc. 4th Congr. Blood Transfus., 388-389.

Friedlander, E. (1959). A ten-year experience of primary resection of the stomach in cases of perforated peptic ulcer. Israel med. $J$. 18, 226-229.

Illingworth, C. F. W., Scott, L. D. W., and Jamieson, R. A. (1944) Acute perforated peptic ulcer: frequency and incidence in the West of Scotland. Brit. med. J., 2, 617-620, 655-658.

Israel Central Bureau of Statistics, Jerusalem. (1959). Statistics of Hospitalisation (1954), p. 11.

Israel Ministry of Health Publication (1960). The Hospitals in Israe (1959) (in Hebrew). Statistical Data on Patients in Hospitals.

Jamieson, R. A. (1955). Acute perforated peptic ulcer: frequency and incidence in the West of Scotland. Brit. med. J., 21, 222-227.

Segi, M., Fujisaku, S., and Kurichara, M. (1959). Mortality for gastric and duodenal ulcer in countries and its geographical correlation to mortality for gastric and intestinal cancer. Schweiz. Z. allg. Path., 22, 777-784.

Statistical Abstract of Israel 1959/60. No. 11, p. 27. Published by the Israel Central Bureau of Statistics, Jerusalem.

Welsh, J. D., and Wolf, S. (1960). Geographical and environmental aspect of peptic ulcer. Amer. J. Med., 29, 754-760. 